120

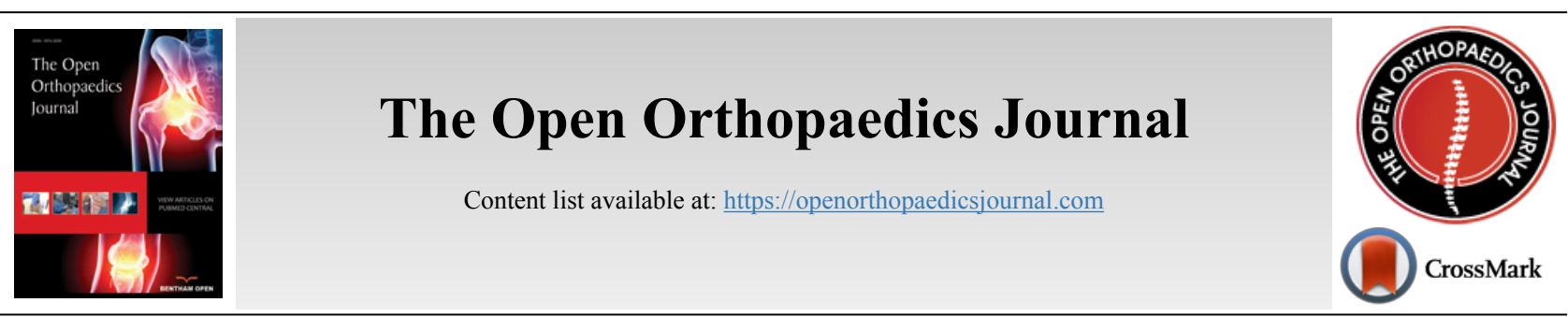

CASE REPORT

\title{
Bifocal Disruption of the Patellar Tendon with Avulsion of the Tibial Tuberosity: A Case Report
}

\author{
Takuya Sekiguchi ${ }^{1,2}$, Yoshihiro Hagiwara, ${ }^{2, *}$, Masahito Honda ${ }^{3}$ and Eiji Itoi ${ }^{2}$ \\ ${ }^{1}$ Department of Orthopedic Surgery, Iwate Prefectural Central Hospital, 1-4-1 Ueda, Morioka, 020-0066, Japan \\ ${ }^{2}$ Department of Orthopedic Surgery, Tohoku University School of Medicine, 1-1 Seiryo-machi, Aoba-ku, Sendai, 980-8574, Japan \\ ${ }^{3}$ Department of Orthopedic Surgery, Takeda General Hospital, 3-27 Yamaga-machi, Aizuwakamatsu, 965-8585, Japan
}

\begin{abstract}
:
Introduction:

Bifocal disruption of the knee extensor system is rare. Coincident bifocal proximal and distal disruptions of the patellar tendon are extremely rare in adults.

Case Report:

A 38-year-old man presented to our clinic with severe right knee pain after falling down the stairs and abruptly bending the right knee. Plain radiographs of this knee showed tibial avulsion and a high riding patella, suggesting underlying Osgood-Schlatter disease, which was also present to a milder degree in the left knee. Magnetic resonance imaging confirmed an avulsion of the tibial tuberosity and showed concomitant avulsion of the patellar tendon without bone marrow edema. Computed tomography showed that the fragment of the tibial tuberosity had a dull-edged margin, and cortical bones were partially exposed. During surgery, the patellar tendon was divided into superficial and deep layers. The superficial layer was peeled from an attachment at the patella, while the deep layer was from the tibia and contained the fragment of the tibial tuberosity. The detached side of the fragment and tibia were coated with dense, fibrous tissue. Surgical repair was performed, with excellent outcomes. Radiographic and intraoperative findings suggested Osgood-Schlatter disease, which might cause avulsion of the tibial tuberosity.

Conclusion:
\end{abstract}

This is the first case of the bifocal proximal and distal rupture of the patellar tendon with the avulsion of the tibial tuberosity. Bifocal disruption of the patellar tendon should be considered in patients presenting with avulsion of the tibial tuberosity and suspected Osgood-Schlatter disease.

Keywords: Knee, Bifocal disruption, Patellar tendon rupture, Tibial Tuberosity, Osgood-Schlatter disease, Patellar tendon.

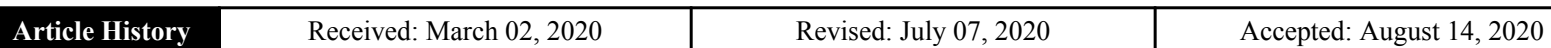

\section{INTRODUCTION}

The patellar tendon is a ligament connecting bone to bone. It originates from the anterior aspect of the inferior pole of the patella and inserts into the tibial tuberosity [1]. Disruption of the knee extensor system is a common injury; patellar tendon rupture is the third most common cause of these injuries, followed by patellar fracture and quadriceps tendon rupture [2]. However, bifocal proximal and distal disruption of the patellar tendon is extremely rare in adults [3, 4]. Kang et al. classified the bifocal disruption of the knee extensor system into five types [3]. We report here, to our knowledge, the first case of bifocal proximal and distal rupture of the patellar tendon with avulsion of the tibial tuberosity.

\footnotetext{
* Address correspondence to this author at the Department of Orthopaedic Surgery, Tohoku University School of Medicine, 1-1 Seiryo-machi, Aoba-ku, Sendai 980-8574, Japan; Tel: +81-22-7177245, Fax: +81-22-7177238;

E-mail: hagi@med.tohoku.ac.jp
}

\section{REPORT OF THE CASE}

A 38-year-old man with no prior history of knee injury presented to our clinic with severe anterior right knee pain. He fell down the stairs with the right knee abruptly bent. He had no significant medical history. Physical examination showed a dimple just below the inferior pole of the patella. Swelling and tenderness were observed around the tibial tuberosity. He could not extend the knee because of pain and muscle weakness. Plain radiographs showed an avulsion of the tibial tuberosity and high riding patella (Fig. 1A). The left knee showed a trace of Osgood-Schlatter disease (Fig. 1B). T2-weighted (T2W) magnetic resonance imaging (MRI) confirmed an avulsion of the tibial tuberosity and revealed concomitant avulsion of the patellar tendon (Fig. 2A). Fat-suppressed T2 weighted imaging (FS-T2W) showed no bone marrow edema around the tibial tuberosity (Fig. 2A). Computed tomography (CT) confirmed 
the avulsion of the tibial tuberosity. The fragment of the tibial tuberosity had a dull-edged margin; cortical bones were partially exposed (Fig. 2C). As these findings were inconsistent with a fresh fracture, the concomitant diagnosis was the bifocal disruption of the patellar tendon, and surgical repair was advised.

At 2 days post injury, the patient underwent surgery by longitudinal incision to expose the tibial tuberosity and patellar tendon. The patellar tendon had separated into two layers. The superficial layer had separated from the patellar origin, correlating with the MRI finding, while the deep layer had separated from the tibia (Fig. 3A). The fragment of the tibial tuberosity was attached to the medial portion of the deep layer. The detached side of the fragment, and the tibia, were coated with dense fibrous tissue (Fig. 3B). After decortication of the detached sites, autologous iliac bone grafts were inserted between the fragment and tibia. The tibial tuberosity was fixed with a cortical screw and a spike-washer (BIOMET $\left.{ }^{\circledR}\right)$. Two sutures with Ethibonds (ETHICON) were secured bilaterally along the deep layer using the Bunnell suture technique. Two transverse drill holes were made just distal to the tuberosity and

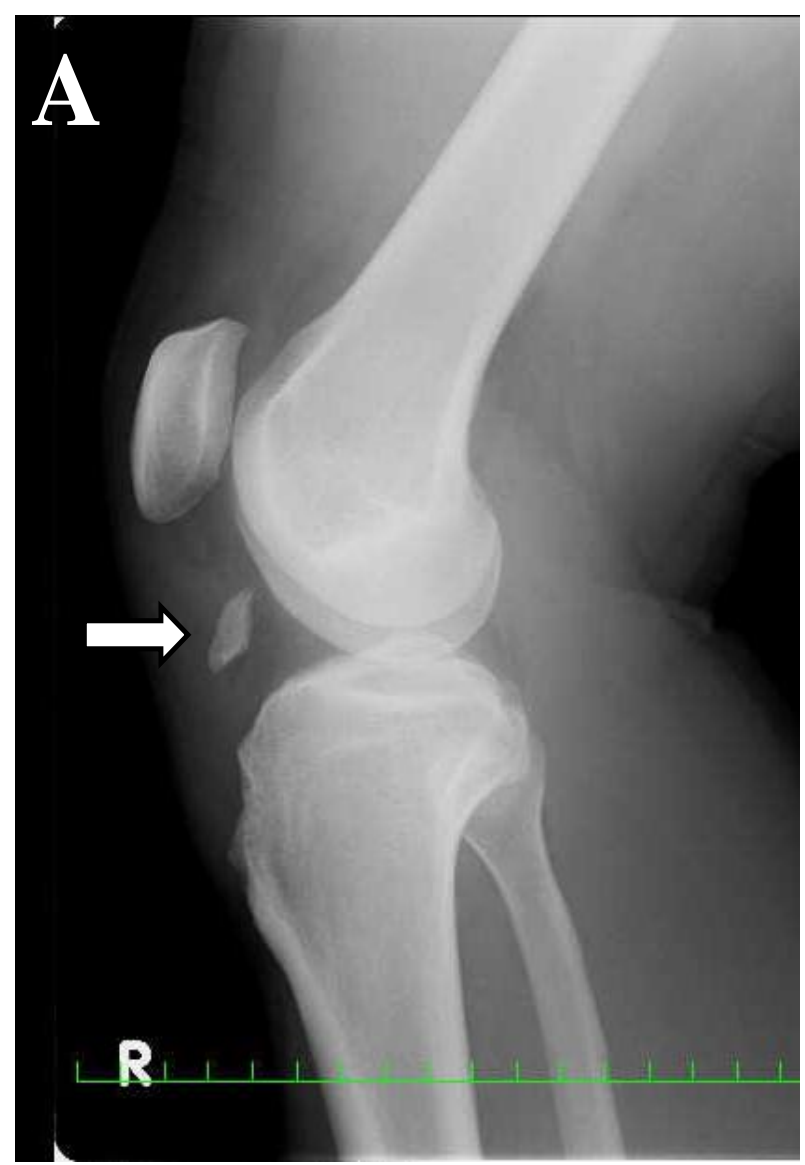

upper two-thirds of the patella. A figure-eight loop with a synthetic ligament (Ai-Medic), passed through the two holes, was made on the patellar surface to completely repair the deep layer (Fig. 3C). The superficial layer was sutured using the Bunnell suture technique with Ethibonds and secured after passing through a transverse drill hole in the patella (Fig. 3D).

Postoperatively, the knee was immobilized with a long leg cast for 1 week, and a rigid knee orthosis thereafter. Partial weight bearing and range of motion exercises were started at 4 weeks after surgery. Three months after surgery, the patient was permitted to remove the orthosis and returned to work. At the 6-month follow-up, T2W MRI showed that the fragment of the tibial tuberosity remained secure, and the patella tendon exhibited good tension (Fig. 4A). At the 12-month follow-up, plain x-ray showed complete bone union of the tibial tuberosity, and slight ossification of the patellar tendon (Fig. 4B). At the 18-month follow-up, the patient had regained a full range of motion with full working ability without pain. The Lysholm knee score was 100, and quadriceps strength assessed by manual muscle testing was normal. The patient provided consent for the publication of this case.

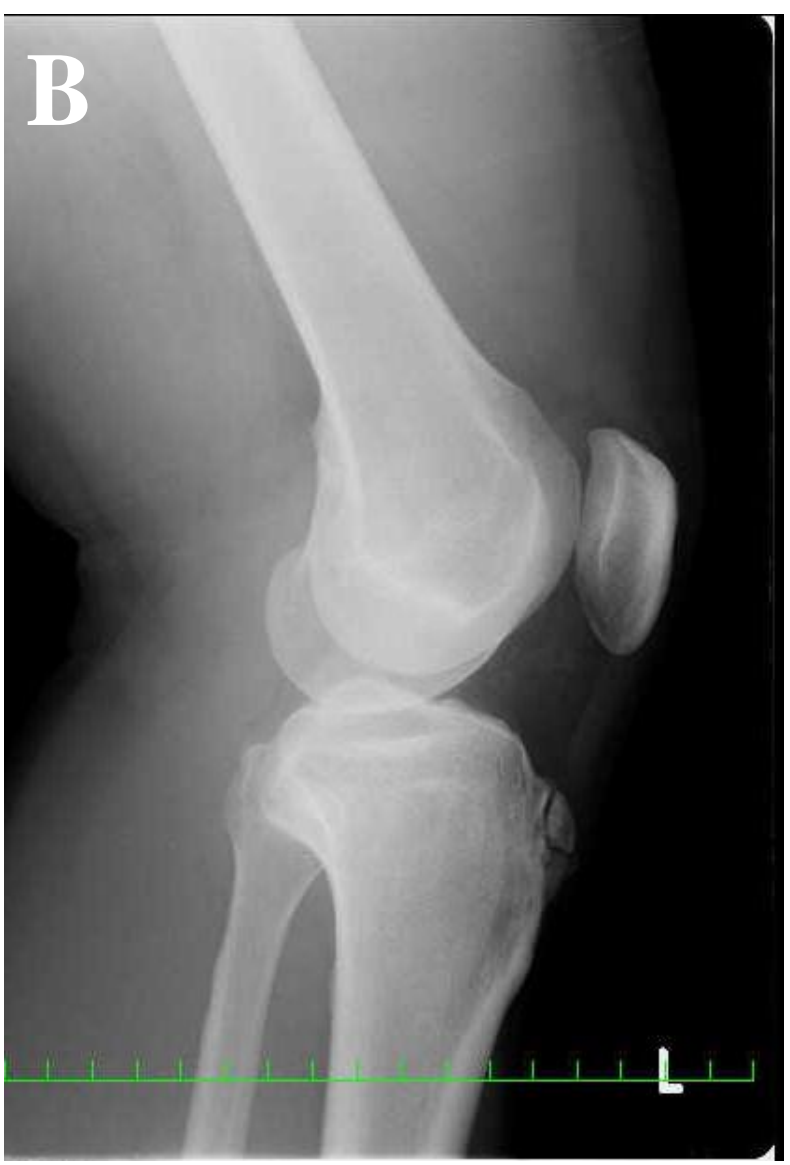

Fig. (1). Lateral plain radiographs of both knees. A: right knee, B: left knee. An avulsion of the tibial tuberosity (arrow) and high riding patella were observed (A). A trace of Osgood-Schlatter disease was observed (B). 

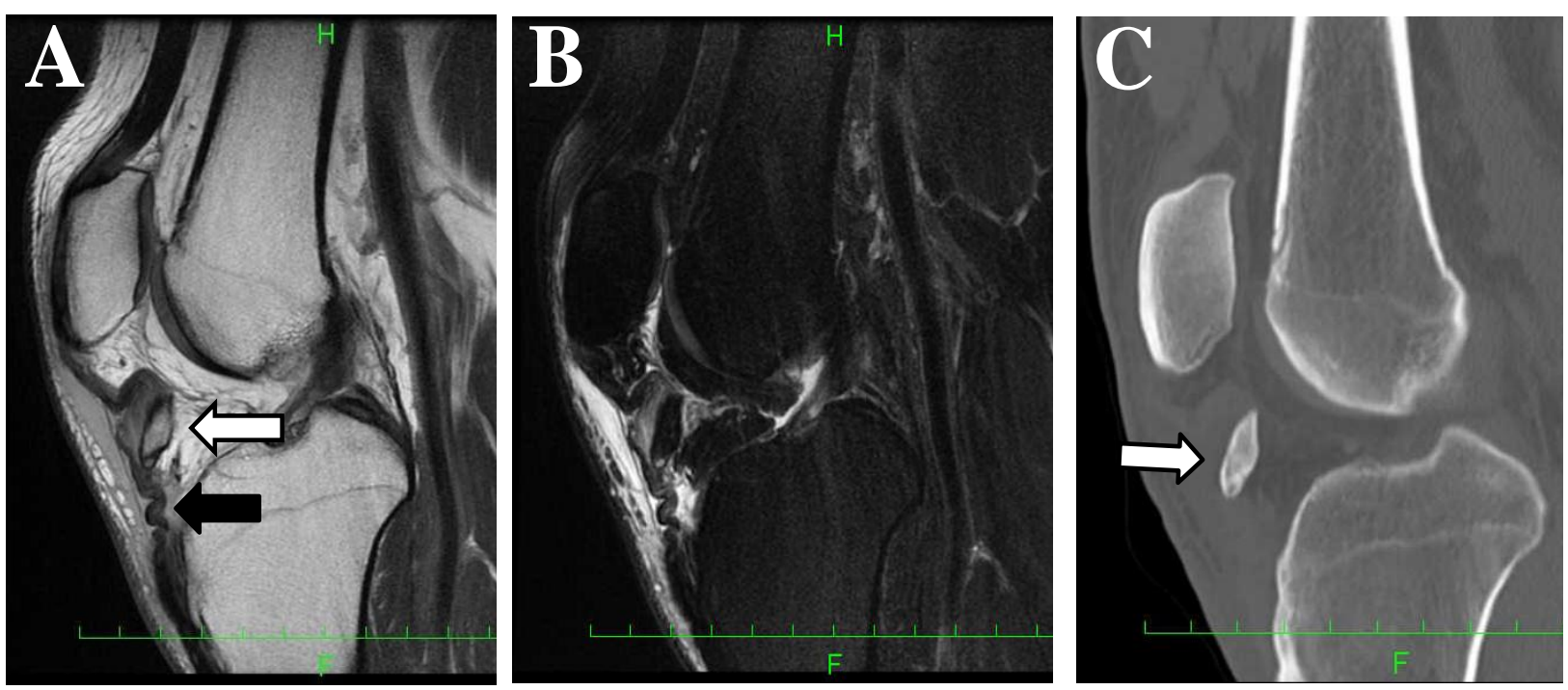

Fig. (2). T2-weighted (A), fat-supressrd T2-weightted MRI (B), and CT (C) images in a sagittal section of the right knee. A: Avulsion of the tibial tuberosity (white arrow) and patellar tendon (black arrow).

B: No bone marrow edema around the tibial tuberosity.

C: The fragment of the tibial tuberosity with a dull-edged margin (white arrow).
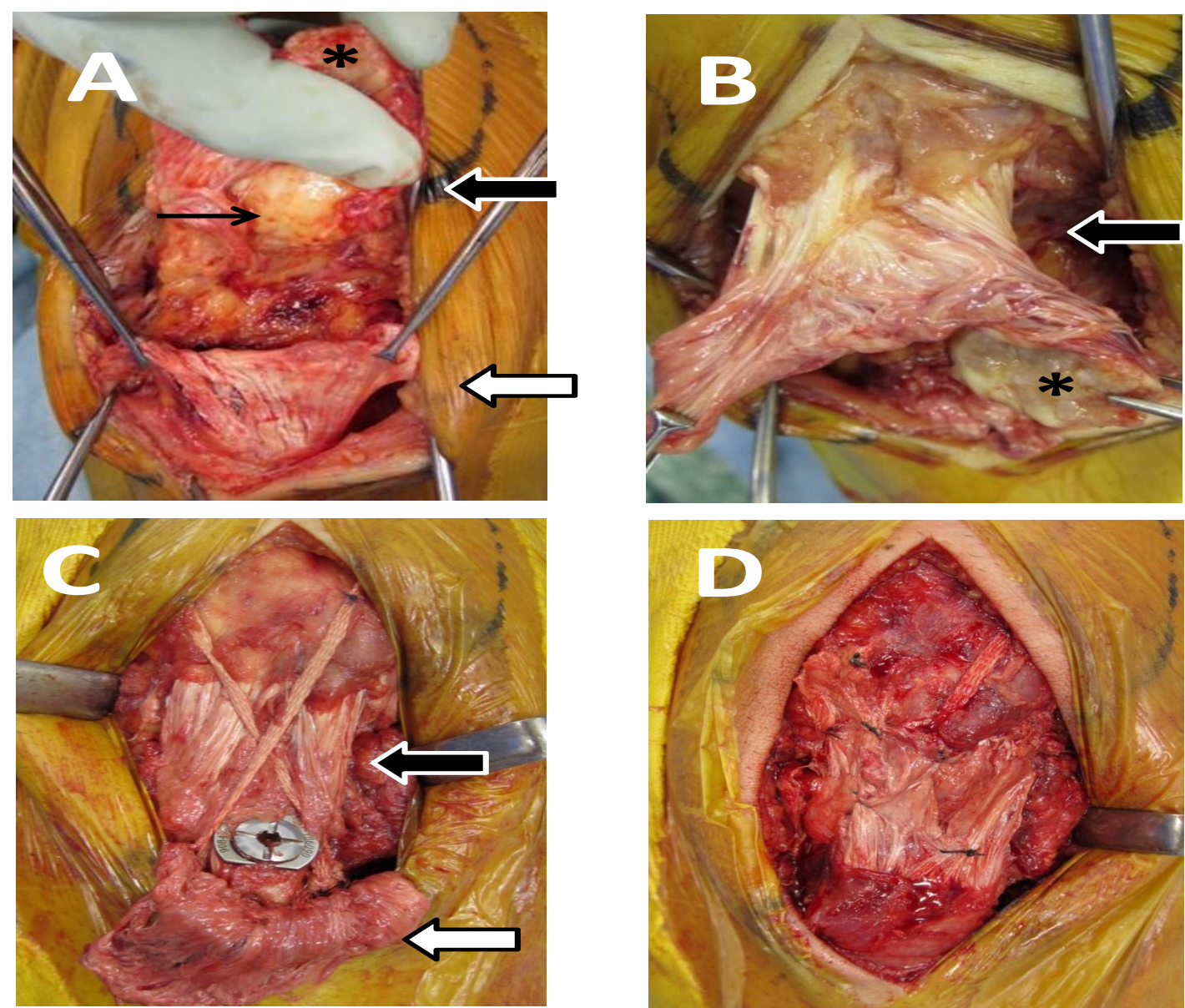

Fig. (3). Intra-operative surgical repair photographs.

Superficial (white arrow) and deep (black arrow) layers of the patellar tendon. The fragment (asterisk) and infrapatellar fat pad (small black arrow) (A). Detached side of the fragment (B). Deep layer reconstruction (C). Superficial layer repair (D). 

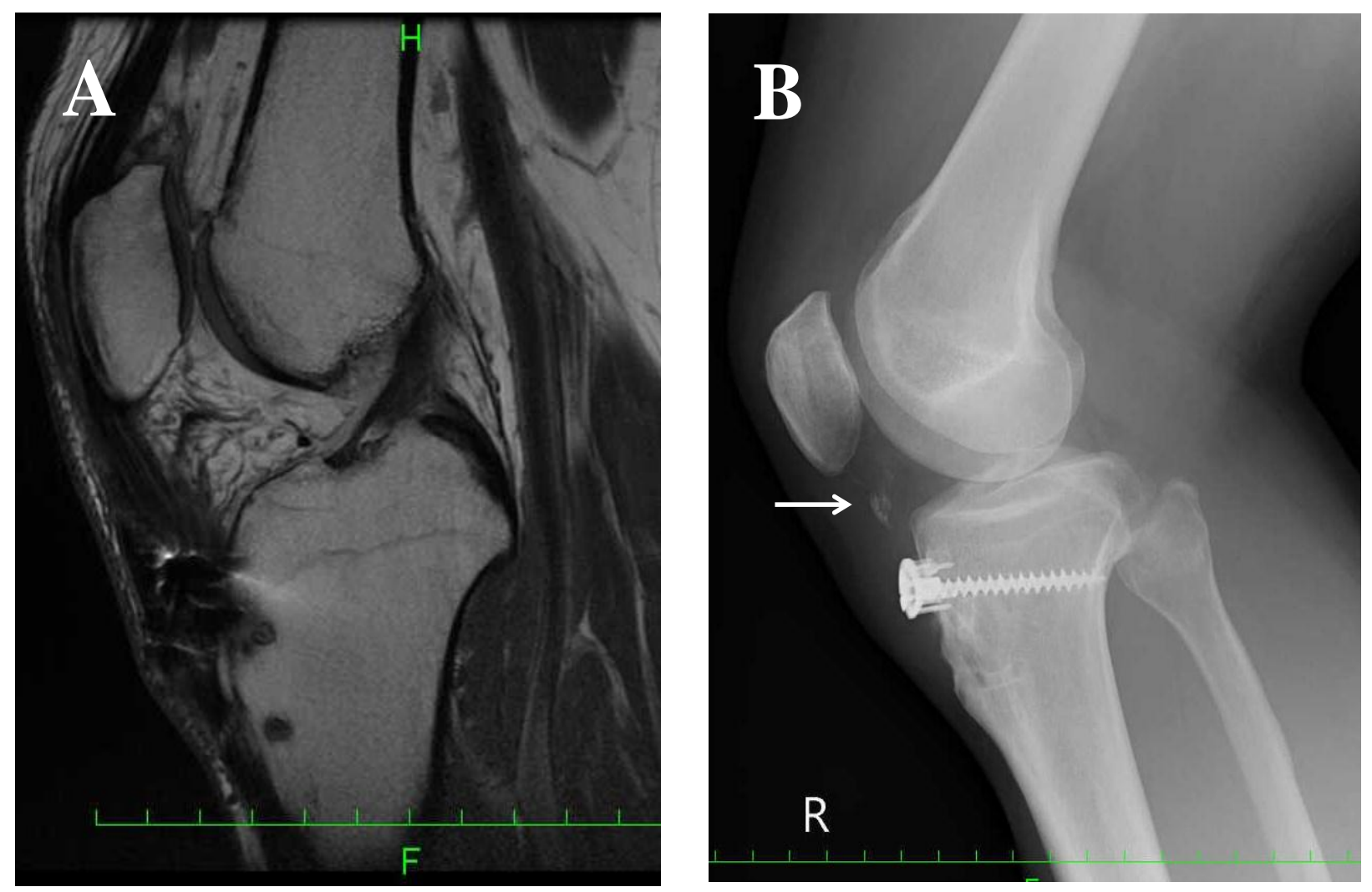

Fig. (4). (A) Sagittal section of T2-weighted MRI and a lateral plain radiograph of the right knee at the six-month follow-up. (B) Twelve-month follow-up plain radiographs of the right knee. Bone union with ectopic patellar tendon ossification (small white arrow).

\section{DISCUSSION}

The most common injury of the knee extensor system is a patellar fracture, followed by quadriceps tendon or patellar tendon rupture [2]. Patellar tendon rupture usually occurs in young patients, especially those in their 20 s $[5,6]$. It occurs not only at the attachment of the patella, but also at the insertion on the tibial tubercle [7 - 10]. The tendon is weakened by microtrauma in athletes, steroid injections, and systemic diseases [7]. Avulsion of the tibial tuberosity is relatively rare and usually occurs in adolescents during growth spurts [11]. The injury is more common in men than in women, and an association with Osgood-Schlatter disease has been suggested $[6,11]$.

The mechanism of tibial tuberosity avulsion and patellar tendon rupture is a sudden contraction of the quadriceps in a flexed knee, or with a fixed foot [12, 13]. Few bifocal disruptions of the knee extensor system have been reported [4, 10,12 - 17]. Kang et al. classified the bifocal disruption of the knee extensor system into five types [3]. The injury type in our study did not match any of these classifications, because of the potential relationship of Osgood-Schlatter disease with avulsion of the tibial tuberosity. Additionally, several common clinical features of other bifocal disruption cases were absent. FS T2W MR imaging techniques are most sensitive for the detection of bone marrow lesions owing to the increased dynamic range of contrast [18]. MRI showed no signal change in the tibia; if there was a fresh fracture of the tibial tuberosity, bone marrow edema should have been evident as a high- intensity area on fsT2W MRI. Furthermore, CT images showed a high-density area around the fragment that was consistent with the cortical bone. Bone density plays a crucial role with respect to the mechanical properties in cancellous and cortical structures. Bone density is defined in several ways, at either the bone tissue or the bone material level [19]. Additionally, the detached side of the fragment and the opposed side of the tibia were coated with dense fibrous tissues, not with cancellous bone. Ogden et al. reported that Osgood-Schlatter disease exhibits the avulsion of a portion of the developing ossification center histologically [11]. This avulsion may occur when chondrocytes undergo hypertrophy in the pre-ossification phase. Once the avulsed portion is pulled away from the cartilage or bone, it may continue to grow and ossify. The intervening area may become fibrous, creating localized nonunion and a characteristic concave defect [11]. In our case, the weakest point was likely located in the tibial tuberosity because of the Osgood-Schlatter disease, and at the tibial attachment of the patella [7]. Sudden flexion of the knee, while contracting the quadriceps muscles, caused avulsion of the superficial layer from an attachment of the patella. However, the deep layer, which was attached to the physis, may have been avulsed from the tibia tubercle with the fragment. Therefore, the injury pattern would have been different from the five classical injury patterns [3].

Patellar tendon ruptures are often misdiagnosed [20]. Siwek et al. reported that $38 \%$ were not diagnosed correctly but were rather misdiagnosed at the first visit [5]. Patellar tendon 
rupture with avulsion from the tibial tubercle has been reported as a complication of Osgood-Schlatter disease [21]. However, the relationship between the proximal disruption of the patellar tendon and Osgood-Schlatter disease has not been reported.

\section{CONCLUSION}

This is, to our knowledge, the first case of bifocal proximal and distal disruption of the patellar tendon as a complication of Osgood-Schlatter disease. Physicians should consider OsgoodSchlatter disease in cases of combined distal and proximal disruption of the patellar tendon to avoid a misdiagnosis.

\section{ETHICS APPROVAL AND CONSENT TO PARTICIPATE}

Not applicable.

\section{HUMAN AND ANIMAL RIGHTS}

Not applicable.

\section{CONSENT FOR PUBLICATION}

Written informed consent was obtained from the patient for publication of this case report and accompanying images.

\section{STANDARD OF REPORTING}

CARE guidelines have been followed.

\section{FUNDING}

None.

\section{CONFLICT OF INTEREST}

The authors have no conflict of interest to declare.

\section{ACKNOWLEDGEMENTS}

Declared none.

\section{REFERENCES}

[1] Bard M, Woods RA, Bartón DH, Corrie JE, Widdowson DA. Sterol mutants of Saccharomyces cerevisiae: chromatographic analyses. Lipids 1977; 12(8): 645-54

[http://dx.doi.org/10.1007/BF02533759] [PMID: 331007]

[2] Enad JG. Patellar tendon ruptures. South Med J 1999; 92(6): 563-6. [http://dx.doi.org/10.1097/00007611-199906000-00003] [PMID: 10372848]

[3] Kang S, Chung PH, Kim YS, Lee HM, Kim JP. Bifocal disruption of the knee extensor mechanism: a case report and literature review. Arch Orthop Trauma Surg 2013; 133(4): 517-21.

[http://dx.doi.org/10.1007/s00402-013-1696-7] [PMID: 23411937]

[4] Chautems R, Michel J, Barraud GE, Burdet A. [Bifocal avulsion of the patellar tendon in an adult: a case report]. Rev Chir Orthop Repar Appar Mot 2001; 87(4): 388-91. [PMID: 11431635]

[5] Siwek CW, Rao JP. Ruptures of the extensor mechanism of the knee joint. J Bone Joint Surg Am 1981; 63(6): 932-7. [http://dx.doi.org/10.2106/00004623-198163060-00010] [PMID: 6985557]

[6] Levi JH, Coleman CR. Fracture of the tibial tubercle. Am J Sports Med 1976; 4(6): 254-63.

[http://dx.doi.org/10.1177/036354657600400604] [PMID: 1008122]

[7] Kricun R, Kricun ME, Arangio GA, Salzman GS, Berman AT. Patellar tendon rupture with underlying systemic disease. AJR Am J Roentgenol 1980; 135(4): 803-7.

[http://dx.doi.org/10.2214/ajr.135.4.803] [PMID: 6778117]

[8] Clark SC, Jones MW, Choudhury RR, Smith E. Bilateral patellar tendon rupture secondary to repeated local steroid injections. J Accid Emerg Med 1995; 12(4): 300-1.

[http://dx.doi.org/10.1136/emj.12.4.300] [PMID: 8775966]

[9] Rose PS, Frassica FJ. Atraumatic bilateral patellar tendon rupture, A case report and review of the literature. J Bone Joint Surg Am 2001; 83(9): 1382-6.

[http://dx.doi.org/10.2106/00004623-200109000-00014] [PMID: 11568202]

[10] Goodier D, Maffulli N, Good J. Tibial tuberosity avulsion associated with patellar tendon avulsion. Acta Orthop Belg 1994; 60(2): 235-7. [PMID: 8053327]

[11] Ogden JA, Tross RB, Murphy MJ. Fractures of the tibial tuberosity in adolescents. J Bone Joint Surg Am 1980; 62(2): 205-15.

[http://dx.doi.org/10.2106/00004623-198062020-00006] [PMID: 7358751]

[12] Frankl U, Wasilewski SA, Healy WL. Avulsion fracture of the tibial tubercle with avulsion of the patellar ligament. Report of two cases. J Bone Joint Surg Am 1990; 72(9): 1411-3.

[http://dx.doi.org/10.2106/00004623-199072090-00024] [PMID: 2229123]

[13] Mayba II. Avulsion fracture of the tibial tubercle apophysis with avulsion of patellar ligament. J Pediatr Orthop 1982; 2(3): 303-5. [http://dx.doi.org/10.1097/01241398-198208000-00012] [PMID: 7130389]

[14] Kaneko K, Miyazaki H, Yamaguchi T. Avulsion fracture of the tibial tubercle with avulsion of the patellar ligament in an adolescent female athlete. Clin J Sport Med 2000; 10(2): 144-5.

[http://dx.doi.org/10.1097/00042752-200004000-00011] [PMID: 10798798]

[15] Chappuis J, Penders W, Cherchel A, Lamraski G. Bifocal disruption of the knee extensor apparatus ("floating patella") in a 72-year-old patient. Acta Orthop Belg 2011; 77(4): 548-51. [PMID: 21954769]

[16] Huber B, Reichenkendler M, Gschwentner M, Kralinger F. Bifocal disruption of the knee extensor apparatus ("floating patella") in a 13year-old patient. Arch Orthop Trauma Surg 2006; 126(4): 275-8. [http://dx.doi.org/10.1007/s00402-005-0047-8] [PMID: 16217671]

[17] Swan K Jr, Rizio L. Combined avulsion fracture of the tibial tubercle and avulsion of the patellar ligament. Orthopedics 2007; 30(7): 571-2. [http://dx.doi.org/10.3928/01477447-20070701-05] [PMID: 17672158]

[18] Del Grande F, Farahani SJ, Carrino JA, Chhabra A. Bone marrow lesions: A systematic diagnostic approach. Indian J Radiol Imaging 2014; 24(3): 279-87.

[http://dx.doi.org/10.4103/0971-3026.137049] [PMID: 25114392]

[19] Zioupos P, Cook RB, Hutchinson JR. Some basic relationships between density values in cancellous and cortical bone. J Biomech 2008; 41(9): 1961-8.

[http://dx.doi.org/10.1016/j.jbiomech.2008.03.025] [PMID: 18501911]

[20] Cree C, Pillai A, Jones B, Blyth M. Bilateral patellar tendon ruptures: a missed diagnosis : case report and literature review. Knee Surg Sports Traumatol Arthrosc 2007; 15(11): 1350-4. [http://dx.doi.org/10.1007/s00167-007-0350-8] [PMID: 17604980]

[21] Bowers KD Jr. Patellar tendon avulsion as a complication of OsgoodSchlatter's disease. Am J Sports Med 1981; 9(6): 356-9. [http://dx.doi.org/10.1177/036354658100900603] [PMID: 7316015]

(C) 2020 Klinkhardt et al.

This is an open access article distributed under the terms of the Creative Commons Attribution 4.0 International Public License (CC-BY 4.0), a copy of which is available at: https://creativecommons.org/licenses/by/4.0/legalcode. This license permits unrestricted use, distribution, and reproduction in any medium, provided the original author and source are credited. 